\title{
MATHEMATICAL PROGRAMMING APPROACH TO UNDERGROUND TIMETABLING PROBLEM FOR MAXIMIZING TIME SYNCHRONIZATION
}

\author{
ANDRES RAMOS \\ MARIA TERESA PENA \\ ANTONIO FERNANDEZ \\ PALOMA CUCALA \\ INSTITUTO DE INVESTIGACIONTECNOLOGICA. ESCUELA TECNICA SUPERIOR DE INGENIERIA \\ UNIVERSIDAD PONTIFICIA COMILLAS
}

Key words: Train timetabling problem, train scheduling, energy saving.

\section{Introduction}

Underground transportation is crucial in big modern cities as a way to achieve a clean, rapid and massif transport. While in peak hours the first objective is to move as many people as possible increasing the train frequency, in off-peak hours other considerations can be taken into account. Energy consumption should be an important issue in the design of train timetables in off-peak hours. Energy saving can be obtained by using regenerative brakes and allowing to synchronize the speed-up of a train exiting a station and the slow-down of a train arriving to another station connected to the same electric section. The arriving train generates electricity that is consumed by the departing train. In fact, given the high frequency of trains in peak hours it is more probable the coincidence of these two processes and, at the same time, is more difficult to change the train schedules by the same reason. Thus the first step in energy saving by changing the off-peak train timetable is maximizing the time overlap between different trains in the same or in different stations connected to the same electrical substation.

By nature the train timetabling problem is highly combinatorial, tightly constrained and very difficult to sol- ve. Two main approaches have been followed by the researchers for solving the problem. One based on mathematical programming techniques. See the papers Caprara et al. (200 I) and Caprara et al. (2002) for the use of Lagrangian relaxation combined with subgradient optimization. See Bussieck (1997) and Nielsen (2006) for mixed integer programming formulations solved directly. In this paper we also use this approach. The other approaches are based on metaheuristic techniques. See Godwin (2006), where they resort to genetic algorithms. Recently, a hybrid approach that combines an evolutionary algorithm for obtaining an initial solution for the optimization problem has been proposed, see Semet (2005), and also constraint programming as solution environment, see Rodriguez (2007).

The paper is organized as follows. In section 2 it is presented the rational of the model. Then, the mathematical formulation of the optimization problem is stated in section 3. In section 4, we develop a case study corresponding to line I of Metro de Madrid. Finally, some conclusions are summarized and some future extensions are suggested in the last section.

\section{Model description}

The model presented here is a particular case of train timetabling problem. Its purpose is maximizing the 
overlapping time between speed-up and slow-down actions of all the trains circulating at any time and located in the same electrical section. As said in the introduction, the model is applied only to trains running during off-peak hours (after $23 \mathrm{~h}$ ) because their schedule can be more easily changed. Moreover, for night trains schedules can be observed almost strictly due to lack of incidences. This model is a useful tool to define the off-peak timetables where energy saving can be an important goal in train scheduling. An experience in the Rome (Italy) underground has reported an energy saving of $15 \%$ without a synchronization objective, see Adinolfi (1998).

The initial schedule is taken as given and the model maximizes the coincidence time while satisfying several operating constraints in order to obtain an implementable timetable.

It is stated as a mixed integer (MIP) optimization problem. The objective function is to maximize the overlapping time between trains that arrive and depart from the same station of from different stations connected to the same electrical substation. The constraints include upper bounds on changes in the current timetable with respect to an initial schedule, while keeping the total travel time of each train, and the computation of the coincidence time between trains. The detection of the overlapping condition requires binary variables and, therefore, integrality conditions, which make the problem very difficult to solve.

Several uses of interest can be devised when solving the optimization problem: i) evaluation of the overlapping time for the initial timetable, ii) maximizing overlapping time, but keeping the train trip time in order to drive at economical speed, similarly to the advertised timetable that exclusively determines departure times, iii) overlapping time when arrival and departure times can be optimized.

\section{Mathematical formulation}

\section{I. Indices}

i train. Trains are supposed to do just a round trip from the beginning to the ending station and then back.

j platform (for example, northbound and southbound) of an underground station. $j=1$, , J, being I the departure platform of the head station and J the opposite platform of the head station.

\subsection{Parameters}

The following data are supposed to be known in advance and correspond to the initial timetable, to intervals of the slow-down and speed-up processes, and to some adjustment parameters that avoid dramatic changes in the final schedule. We use lower case letters to define the parameters.

$a_{i j}, d_{i j}$ initial arrival and departure times of train $i$ at platform $j[\mathrm{~s}]$

sd, su slow-down and speed-up times of any train at any platform' $[\mathrm{s}]$

$\Delta s_{j}, \nabla s_{j}$, maximum and minimum changes in stopping time at platform $j[\mathrm{~s}]$

$\Delta t_{j}, \nabla t_{j}$, maximum and minimum changes in travelling time at platform $j[\mathrm{~s}]$

$\Delta$ tt maximum increment in total trip time for any train $[\mathrm{s}]$

$P_{j j^{\prime}}$ penalty factor introduced to consider somehow the loss in the electricity transferred between trains at different platforms $j$ and $j$ ' although both belong to the same electrical section [p.u.]. If two platforms belong to different electrical sections $p_{j j^{\prime}}=0$.

\subsection{Variables}

The variables of the optimization problem are written in capital and Greek letters and correspond to the following ones:

$A_{i j}, D_{i j}$ arrival and departure times of train $i$ at platform $j[\mathrm{~s}]$

$\delta_{i j i^{\prime} j^{\prime}}$ binary variable that indicates whether there is or not ( $1 / 0$, respectively) coincidence between the slowdown interval of train $i$ at platform $j$ and the speedup interval of train i' at platform $j$

$T_{i j i j^{\prime}}$ overlapping time between the slow-down and speed-up intervals of train $i$ at platform $j$ and train $i$ ' at platform j', respectively [s]

$B_{i j}, C_{i j}$ change in arrival and departure times of train $i$ at platform $j$ with respect to the initial timetable [s]

\footnotetext{
'They can easily be particularized for each platform and even train type to take into consideration their specific characteristics.
} 


\subsection{Constraints}

The following constraints take into account the operating conditions of the trains.

- Change in the stopping time with respect to the initial schedule for each train $i$ at platform $j$ has to be bounded by the corresponding bounds

$$
\nabla s_{j} \leq\left(D_{i j}-A_{i j}\right)-\left(d_{i j}-a_{i j}\right) \leq \Delta s_{j} \quad \forall i j
$$

The stopping time of any train at the terminal station is considered to take a constant time. Therefore, this constraint is not formulated at the terminal station of the line. Each time a train departs from the head station is considered a new train.

- Change in the travelling time for each train $i$ at platform $j$ with respect to the initial schedule has to be bounded by the corresponding bounds

$$
\nabla t_{j} \leq\left(A_{i j}-D_{i j-1}\right)-\left(a_{i j}-d_{i j-1}\right) \leq \Delta t_{j} \quad \forall i j
$$

The platform change of the train at the terminal station is considered to take a constant time. Therefore, this constraint is not formulated for the terminal station of the line.

- Change in the total trip time for each train $i$ and in each way with respect to the initial schedule has to be bounded by the corresponding bounds

$$
\begin{aligned}
& \left(A_{i j / 2}-D_{i l}\right)-\left(a_{i j / 2}-d_{i l}\right) \leq \Delta t \\
& \left(A_{i j}-D_{i j / 2} J\right)-\left(a_{i j}-d_{i J / 2}\right) \leq \Delta t
\end{aligned}
$$

One way is from the departure platform at the head station to same side platform at the terminal station, $/ / 2$, and the other way is from other side platform at the terminal station $J / 2+$ I to the opposite platform at the head station $\mathrm{J}$,

\section{- Computation of overlapping time}

Before writing the constraints that allow the computation of the overlapping time let us describe the different possibilities of train coincidence. Let us define $A_{i j}^{-}=A_{i j}-s d$ the beginning of the slowdown process before arriving to a platform $D_{i j j^{\prime}}=D_{i j^{\prime}}+$ su the end of the speed-up process after departure of a platform. The six combinations and their overlapping time are presented in the following table, where departure times are in

\begin{tabular}{|c|c|c|c|}
\hline Case & Sequence & & Overlapping time \\
\hline 1 & $D_{i j}, A_{i j}^{-}, A_{i j}, D_{i j}^{+}$ & {$[[]]$} & $A_{i j}-A_{i j}^{-}=s d$ \\
\hline 2 & $A_{i j}^{-}, D_{i j}, D_{i j}^{+}, A_{i j}$ & {$[[]]$} & $D_{i j}^{+}-D_{i j}=s u$ \\
\hline 3 & $D_{i j}, A_{i j}^{-}, D_{i j}^{+}, A_{i j}$ & {$[[]]$} & $D_{i j}^{+}-A_{i j}^{-}$ \\
\hline 4 & $A_{i j}^{-}, D_{i j}, A_{i j}, D_{i j}^{+}$ & {$[[]]$} & $A_{i j}-D_{i j}$ \\
\hline 5 & $D_{i j}, D_{i j}^{+}, A_{i j}^{-}, A_{i j}$ & {[][]} & 0 \\
\hline 6 & $A_{i j}^{-}, A_{i j}, D_{i j}, D_{i j}^{+}$ & {[][]} & 0 \\
\hline
\end{tabular}

black colour and arrival times are in blue.

For example, there is no coincidence if a train begins the slow-down process after the speed-up process of another train $\left(A_{i j}^{-} \geq D^{+}{ }_{i j}\right.$, case [5]) or if a train departs after the arrival of another train $\left(D_{i j^{\prime}} \geq A_{i j}\right.$, case [6]). These cases can be modelled as a logical implication

$$
A_{i j}^{-} \geq D_{i^{\prime j^{\prime}}}^{+} \text {or } D_{i j^{\prime} j^{\prime}} \geq A_{i j} \Rightarrow \delta_{i i^{\prime j^{\prime}}}=0
$$

being $\boldsymbol{\delta}_{i j j^{\prime}}$ the binary variable that indicates the coincidence condition. $\delta_{j i i^{\prime}}=$ I means coincidence.

This implication can be modelled by the linear constraints

$$
\begin{array}{ll}
A_{i j}^{-}-D_{i i^{\prime}}^{+} \leq M\left(I-\delta_{i j i^{\prime} j^{\prime}}\right) & \forall i i i^{\prime} j^{\prime} \\
D_{i j^{\prime} j^{\prime}}-A_{i j} \leq M\left(I-\delta_{i j j^{\prime} j^{\prime}}\right) & \forall i j j^{\prime} j^{\prime}
\end{array}
$$

being $M=\max \left(\left|d_{i^{\prime j^{\prime}}}-a_{i j}-\Delta s_{j}+\nabla s_{j}\right|\right)+s u+s d$ an upper bound of the constraint.

In the other cases [I to 4] and if we define $B_{i j i t}$ and $E_{i j i i^{\prime}}$ as the beginning and end of overlapping time between the slow-down interval of train $i$ at platform $j$ and speed-up internal of train $i$ ' at platform $j$ ', the overlapping time can be calculated as

$$
\begin{aligned}
& B_{i j i^{\prime} j^{\prime}}=\max \left(D_{i j^{\prime}}, A_{i j}^{-}\right) \quad \forall i j^{\prime} j^{\prime} j^{\prime} \\
& E_{i j i^{\prime} j^{\prime}}=\min \left(D_{i^{\prime} j^{\prime}}^{+}, A_{i j}\right) \quad \forall i j^{\prime} j^{\prime} j^{\prime} \\
& T_{i j j^{\prime} j^{\prime}} \leq M^{\prime} \delta_{i j i^{\prime} j^{\prime}} \quad \forall i j^{\prime} j^{\prime} j^{\prime} \\
& T_{i j i^{\prime} j^{\prime}} \leq\left(E_{i j i^{\prime} j^{\prime}}-B_{i j i^{\prime} j^{\prime}}\right)+M\left(I-\delta_{i j i^{\prime} j^{\prime}}\right) \quad \forall i{i j i j^{\prime} j^{\prime}}^{\prime}
\end{aligned}
$$

being the maximum overlapping time the 
slow-down or speed-up time of any train, $M^{\prime}=\min (s u, s d)$. In fact, we can disregard the auxiliary variables $B_{i j j^{\prime} j^{\prime}}$ and $E_{i j i^{\prime} j^{\prime}}$ and formulate the constraint as

$$
\begin{aligned}
& T_{i j j^{\prime} j^{\prime}} \leq M^{\prime} \delta_{i j i^{\prime} j^{\prime}} \quad \forall i j^{\prime} j^{\prime} j^{\prime} \\
& T_{i j i^{\prime} j^{\prime}} \leq D_{i^{\prime} j^{\prime}}^{+}-D_{i i^{\prime} j^{\prime}}+M\left(I-\delta_{i j i^{\prime} j^{\prime}}\right) \quad \forall i j i^{\prime} j^{\prime} \\
& T_{i j i^{\prime} j^{\prime}} \leq D_{i^{\prime} j^{\prime}}^{+}-A_{i j}^{-}+M\left(I-\delta_{i j j^{\prime} j^{\prime}}\right) \quad \forall i i j^{\prime} j^{\prime} \\
& T_{i j i^{\prime} j^{\prime}} \leq A_{i j}-D_{i j^{\prime} j^{\prime}}+M\left(I-\delta_{i j i^{\prime} j^{\prime}}\right) \quad \forall i i i^{\prime} j^{\prime} \\
& T_{i j i^{\prime} j^{\prime}} \leq A_{i j}-A_{i j}^{-}+M\left(I-\delta_{i j i^{\prime} j^{\prime}}\right) \quad \forall i i j^{\prime} j^{\prime} \\
& T_{i j i^{\prime} j^{\prime}} \leq M^{\prime} \delta_{i j i^{\prime} j^{\prime}} \quad \forall i j j^{\prime} j^{\prime} \\
& T_{i j i^{\prime} j^{\prime}} \leq s u \delta_{i j i^{\prime} j^{\prime}} \quad \forall i j j^{\prime} j^{\prime} \\
& T_{i j i^{\prime} j^{\prime}} \leq D_{i^{\prime} j^{\prime}}^{+}-A_{i j}^{-}+M\left(I-\delta_{i j j^{\prime} j^{\prime}}\right) \quad \forall i j j^{\prime} j^{\prime} j^{\prime} \\
& T_{i j i^{\prime} j^{\prime}} \leq A_{i j}-D_{i^{\prime} j^{\prime}}+M\left(I-\delta_{i j i^{\prime} j^{\prime}}\right) \quad \forall i i j^{\prime} j^{\prime} \\
& T_{i j i^{\prime} j^{\prime}} \leq s d \delta_{i j i^{\prime} j^{\prime}} \quad \forall i j^{\prime} j^{\prime} j^{\prime}
\end{aligned}
$$

It can be observed that the third and fourth equations of the set [8] and the condition of non negative overlapping time $T_{i i^{\prime} j^{\prime}} \geq 0$ turn superfluous equations [5]. In the same way, the second and fifth equations of set [8] can be substituted by the first equation of this set.

$$
\begin{array}{ll}
T_{i j i^{\prime} j^{\prime}} \leq M^{\prime} \delta_{i j i^{\prime} j^{\prime}} & \forall i i j^{\prime} j^{\prime} \\
T_{i j i^{\prime} j^{\prime}} \leq D_{i^{\prime} j^{\prime}{ }^{\prime}}^{+}-A_{i j}^{-}+M\left(I-\delta_{i j i^{\prime} j^{\prime}}\right) & \forall i i j^{\prime} j^{\prime} \\
T_{i j i^{\prime} j^{\prime}} \leq A_{i j}-D_{i^{\prime} j^{\prime}}+M\left(I-\delta_{i j i^{\prime} j^{\prime}}\right) & \forall i j j^{\prime} j^{\prime}
\end{array}
$$

- Finally, a set of equations are added to avoid changes in the timetable that do not improve the overlapping time

$$
\begin{array}{ll}
-B_{i j} \leq A_{i j}-a_{i j} \leq B_{i j} & \forall i j \\
-C_{i j} \leq D_{i j}-d_{i j} \leq C_{i j} & \forall i j
\end{array}
$$

where variables $B_{i j}$ and $C_{i j}$ correspond to changes in arrival and departure times, respectively, with respect to the initial timetable. Their sum is introduced in the objective function with a very small penalty $\varepsilon$.

\subsection{Objective function}

The objective function maximizes the total overlapping time

$$
\max \sum_{i j i^{\prime} j^{\prime}} p_{j j^{\prime}} T_{i j i^{\prime} j^{\prime}}-\varepsilon \sum_{i j}\left(B_{i j}+C_{i j}\right)
$$

\subsection{Mathematical problem}

The MIP optimization problem that maximizes the total overlapping time between the slow-down and speed-up processes of different trains can be stated as

$$
\begin{aligned}
& \max \sum_{i j i^{\prime} j^{\prime}} p_{i j j^{\prime}} T_{i i^{\prime} j^{\prime}}-\varepsilon \sum_{i j}\left(B_{i j}+C_{i j}\right) \\
& \nabla s_{j} \leq\left(D_{i j}-A_{i j}\right)-\left(d_{i j}-a_{i j}\right) \leq \Delta s_{j} \quad \forall i j \\
& \nabla t_{j} \leq\left(A_{i j}-D_{i j-1}\right)-\left(a_{i j}-d_{i j-1}\right) \leq \Delta t_{j} \quad \forall i j \\
& \left(A_{i J / 2}-D_{i l}\right)-\left(a_{i j / 2}-d_{i i}\right) \leq \Delta t t \quad \forall i \\
& \left(A_{i j}-D_{i j / 2+1}\right)-\left(a_{i j}-d_{i j / 2+1}\right) \leq \Delta t t \quad \forall i \\
& T_{i j i^{\prime} j^{\prime}} \leq M^{\prime} \delta_{i j i^{\prime} j^{\prime}} \\
& \forall i j^{\prime} j^{\prime}{ }^{\prime} \\
& T_{i j i^{\prime} j^{\prime}} \leq D_{i^{\prime j^{\prime}}}^{+}-A_{i j}^{-}+M\left(I-\delta_{i i^{\prime} j^{\prime}}\right) \quad \forall i i j^{\prime} j^{\prime} \\
& T_{i j i^{\prime} j^{\prime}} \leq A_{i j}-D_{i j^{\prime} j^{\prime}}+M\left(I-\delta_{i j i^{\prime} j^{\prime}}\right) \quad \forall i i^{\prime} j^{\prime} j^{\prime} \\
& -B_{i j} \leq A_{i j}-a_{i j} \leq B_{i j} \quad \forall i j \\
& -C_{i j} \leq D_{i j}-d_{i j} \leq C_{i j} \quad \forall i j \\
& A_{i j j^{\prime}}, D_{i^{\prime} j^{\prime}}, T_{i j i^{\prime} j^{\prime}}, B_{i j}, C_{i j} \geq 0, \delta_{i j i^{\prime} j^{\prime}} \in\{0,1\}
\end{aligned}
$$

\begin{tabular}{|l|r|r|}
\hline & & $I=\mid 4, J=54$ \\
\hline Contraints & $8 I J+2 I+\left.\left.3\right|^{2}\right|^{2}$ & $\mid 720684$ \\
\hline Continuous variables & $4 I J+\left.1^{2}\right|^{2}$ & $1 \mid 46096$ \\
\hline Binary variables & $\left.\right|^{2} J^{2}$ & $57 \mid 536$ \\
\hline
\end{tabular}

The size of the problem is parameterized in this table and estimated for $I=14$ night trains, and $J=54$ platforms (corresponding to 27 stations).

To avoid the curse of dimensionality in the size of the problem the possible combinations between different trains at platforms can be substantially reduced by dealing only with those trains that are relative close in the original timetable, iji'j' $\in c($ i.j, i',j'), being $c($ i.j, i', j') the set of close trains. For example, in the case study presented in the following section the size of the problem is approximately 7,700 constraints, 4,200 continuous variables and 600 binary variables very far from the previous estimation. The set of close trains is determined by the model given a scalar specified by the user. 


\subsection{Implementation}

The model has been written in GAMS, see Brooke (2005), and solved by CPLEX I0. I, see ILOG, under a PC at $1.83 \mathrm{GHz}$ with I GB of RAM memory running the Microsoft Windows XP operating system. A Microsoft Excel interface has been used for input data and output results.

In the following table are presented some results of the mathematical problem for different maximum solution times.

It can be observed that the improvement in the MIP optimal solution is very low with respect to the maximum solution time. The difficulty in solving a MIP problem is somehow measured by the relative tolerance or integrality gap, which in this case is high. The number of iterations and explored nodes are proportional to the solution time.

\section{Case study}

This train timetabling model has been tested with a realistic case corresponding to line I of Metro de Madrid. As mentioned in the introduction, the optimization problem may be used for:

- Evaluation of the overlapping time for the initial arrival and departure times

The initial timetable had 0 seconds of overlapping time.

- Maximizing overlapping time, but keeping the train trip time in order to drive at economical speed, similarly to the advertised timetable that exclusively determines departure times

For this case the overlapping time reached 1.30 hours (within a solution time of $60 \mathrm{~s}$ ).

- Optimization of overlapping time when arrival
Figure I

Evolution of the relative tolerance with respect to the maximum solution time

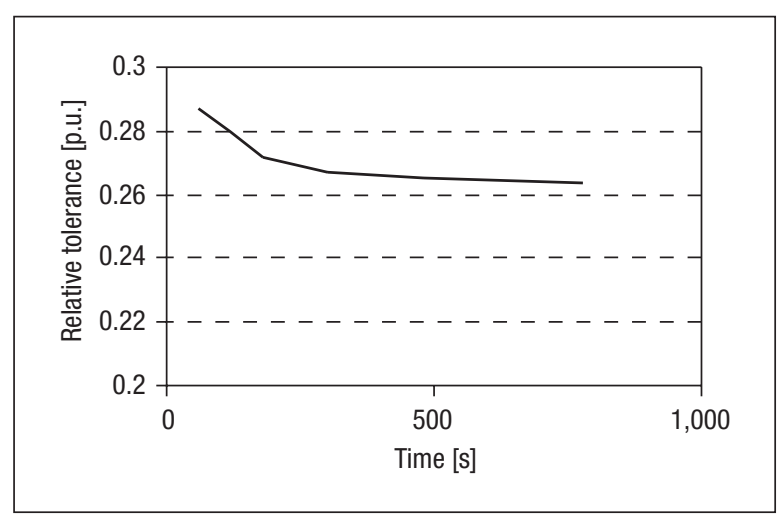

and departure times are optimized

If arrival times as well as departure times can be scheduled, the overlapping time can be slightly improved up to 1.36 hours (within a solution time of $60 \mathrm{~s}$ ).

These results show that time coincidence can be increased dramatically and, therefore, energy saving by train synchronization. Although the MIP solution obtained in a certain clock time can not be proved to be optimal it represents a dramatic improvement in the objective function with respect to the overlapping time of the initial timetable. Besides, much of the overlapping time can be achieved with no modifications of the current advertised timetables, only modifying the internal operation of the trains without modifying the public perception.

The following coloured table show where the changes in the timetable have been made for the second case mentioned before. Because of the huge amount of data, only the stations connected to a given substation are shown. The trains that simultaneously overlap when slow down and speed up are labelled with the same colour.

The following table shows how much overlapping ti-

\begin{tabular}{|l|c|c|c|c|c|c|}
\hline & $\mathbf{6 0} \mathbf{s}$ & $\mathbf{1 2 0} \mathbf{s}$ & $\mathbf{1 8 0 ~ s}$ & $\mathbf{3 0 0} \mathbf{s}$ & $\mathbf{4 8 0} \mathbf{~ s}$ & $\mathbf{7 8 0} \mathbf{~ s}$ \\
\hline MIP solution [s] & 4909.645 & 4932.533 & 4957.533 & 4972.661 & 4972.587 & 4972.661 \\
\hline LP Relaxation [s] & 6320.811 & 6312.254 & 6305.047 & 6298.265 & 6290.912 & 6285.199 \\
\hline Relative Tolerance [p.u.] & 0.287427 & 0.279718 & 0.271811 & 0.266578 & 0.265119 & 0.263951 \\
\hline Iterations & 136564 & 283620 & 452945 & 708080 & 1171531 & 1886725 \\
\hline Nodes & 18701 & 38101 & 60701 & 95301 & 157401 & 247801 \\
\hline
\end{tabular}


Table I

Coincident trains when the timetable is calculated optimizing only departure times

\begin{tabular}{|c|c|c|c|c|c|c|c|c|c|c|c|c|c|}
\hline \multicolumn{2}{|c|}{ Calculated Schedule } & \multicolumn{12}{|c|}{ Stations } \\
\hline Trains & Events & $|A|$ & SI & TMI & AMI & ATI & ARI & AR2 & AT2 & AM2 & TM2 & S2 & A2 \\
\hline \multirow{2}{*}{$\mathrm{NI}$} & Arrival & $23: 19: 00$ & $23: 19: 55$ & $3: 21: 50$ & $23: 22: 45$ & $23: 24: 40$ & $3: 25: 35$ & 24:06:40 & $24: 07: 35$ & $24: 08: 30$ & $24: 10: 40$ & $24: 12: 35$ & $24: 14: 00$ \\
\hline & Departure & $23: 19: 10$ & $23: 20: 05$ & $23: 22: 00$ & $23: 22: 55$ & $23: 24: 50$ & $23: 25: 45$ & 24:06:50 & $24: 07: 45$ & $24: 08: 55$ & $24: 10: 50$ & $24: 13: 15$ & $24: 14: 10$ \\
\hline \multirow{2}{*}{ N2 } & Arrival & $23: 26: 00$ & $23: 27: 55$ & $23: 28: 49$ & $23: 30: 45$ & $23: 31: 39$ & $23: 32: 34$ & $24: 14: 05$ & $24: 15: 00$ & $24: 16: 55$ & $24: 17: 50$ & $24: 19: 45$ & $24: 20: 40$ \\
\hline & Departure & $23: 26: 10$ & & 23:29:00 & $23: 30: 55$ & $23: 31: 50$ & $23: 33: 08$ & $24: 14: 15$ & $24: 15: 10$ & $24: 17: 05$ & $24: 18: 00$ & $24: 19: 55$ & $24: 20: 50$ \\
\hline \multirow{2}{*}{ N3 } & Arrival & $23: 34: 28$ & $23: 35: 24$ & $23: 37: 18$ & $23: 38: 13$ & 23:40:09 & $23: 41: 04$ & $24: 28: 4 \mid$ & $24: 30: 06$ & $24: 32: 01$ & $24: 32: 56$ & $24: 34: 51$ & $24: 35: 46$ \\
\hline & Departure & $23: 34: 39$ & $23: 35: 34$ & $23: 37: 29$ & $23: 38: 24$ & $23: 40: 19$ & $23: 41: 19$ & $24: 29: 21$ & $24: 30: 15$ & $24: 32: 10$ & $24: 33: 06$ & $24: 35: 01$ & $24: 35: 55$ \\
\hline \multirow{2}{*}{ N4 } & Arrival & $23: 41: 29$ & $23: 43: 24$ & $23: 44: 19$ & $23: 46: 14$ & 23:47:09 & 23:48:04 & $24: 43: 48$ & $24: 45: 13$ & $24: 47: 08$ & $24: 48: 03$ & $24: 49: 58$ & $24: 50: 53$ \\
\hline & Departure & $23: 41: 39$ & & $23: 44: 29$ & $23: 46: 24$ & $23: 47: 19$ & $23: 48: 19$ & $24: 44: 27$ & $24: 45: 23$ & $24: 47: 18$ & $24: 48: 13$ & $24: 50: 08$ & $24: 51: 03$ \\
\hline \multirow{2}{*}{ N5 } & Arrival & $23: 49: 59$ & $23: 50: 55$ & $23: 52: 55$ & $23: 53: 49$ & $23: 55: 45$ & $23: 56: 40$ & $24: 57: 58$ & $24: 59: 23$ & $25: 01: 30$ & $02: 25$ & $25: 04: 20$ & $25: 05: 15$ \\
\hline & Departure & $23: 50: 09$ & $23: 51: 10$ & $23: 53: 05$ & $23: 53: 59$ & $23: 55: 55$ & $23: 56: 50$ & $24: 58: 38$ & $24: 59: 45$ & $25: 01: 40$ & $25: 02: 35$ & $25: 04: 30$ & $25: 05: 25$ \\
\hline \multirow{2}{*}{ N6 } & Arrival & $23: 56: 40$ & $23: 58: 35$ & $23: 59: 30$ & $24: 01: 25$ & $24: 02: 20$ & $24: 03: 20$ & $25: 13: 15$ & & $25: 16: 36$ & $25: 17: 31$ & $25: 19: 26$ & $25: 20: 21$ \\
\hline & Departure & 23:56:50 & $23: 58: 45$ & 23:59:40 & $24: 01: 35$ & $24: 02: 35$ & $24: 03: 30$ & 25:1 $3: 55$ & $25: 14: 50$ & $25: 16: 45$ & $25: 17: 41$ & $25: 19: 36$ & $25: 20: 30$ \\
\hline \multirow{2}{*}{ N7 } & Arrival & $24: 04: 20$ & $24: 05: 15$ & $24: 07: 10$ & $24: 08: 05$ & $24: 10: 00$ & $24: 11: 10$ & $23: 20: 55$ & $23: 22: 15$ & $23: 23: 10$ & $23: 25: 05$ & $23: 27: 00$ & \\
\hline & Departure & 24:04:29 & $24: 05: 25$ & 24:07:20 & $24: 08: 15$ & $24: 10: 25$ & $24: 11: 50$ & & $23: 22: 25$ & $23: 23: 20$ & & 23:27:35 & $23: 28: 30$ \\
\hline \multirow{2}{*}{ N8 } & Arrival & $24: 11: 10$ & $24: 13: 35$ & $24: 14: 30$ & $24: 16: 25$ & $24: 17: 20$ & $24: 18: 15$ & $23: 28: 00$ & $23: 29: 13$ & $23: 31: 09$ & $23: 32: 03$ & $23: 33: 58$ & $23: 34: 54$ \\
\hline & Departure & $24: 11: 50$ & $24: 13: 45$ & $24: 14: 40$ & $24: 16: 35$ & $24: 17: 30$ & $24: 18: 50$ & $23: 28: 29$ & $23: 29: 24$ & $23: 31: 19$ & $23: 32: 14$ & $23: 34: 09$ & $3: 35: 04$ \\
\hline \multirow{2}{*}{ N9 } & Arrival & $24: 26: 50$ & $24: 28: 45$ & $24: 29: 40$ & $24: 31: 35$ & $24: 32: 30$ & $24: 33: 25$ & $23: 36: 18$ & $23: 37: 42$ & $23: 38: 37$ & $23: 40: 34$ & $23: 42: 28$ & \\
\hline & Departure & $24: 27: 00$ & $24: 28: 55$ & $24: 29: 49$ & & $24: 32: 40$ & $24: 33: 34$ & $23: 36: 58$ & $23: 37: 53$ & $23: 38: 49$ & $23: 40: 44$ & $23: 43: 04$ & 23:44:00 \\
\hline \multirow{2}{*}{ NIO } & Arrival & $24: 41: 57$ & $24: 43: 52$ & $24: 44: 47$ & $24: 46: 42$ & $24: 47: 37$ & $24: 48: 32$ & $25: 28: 30$ & $25: 29: 47$ & $25: 31: 42$ & $25: 32: 37$ & $25: 34: 32$ & $25: 35: 27$ \\
\hline & Departure & $24: 42: 06$ & $24: 44: 01$ & $24: 44: 57$ & $24: 46: 52$ & $24: 47: 47$ & $24: 48: 42$ & $25: 29: 01$ & $25: 29: 57$ & $25: 31: 52$ & $25: 32: 47$ & $25: 34: 42$ & $25: 35: 37$ \\
\hline \multirow{2}{*}{ NII } & Arrival & $24: 56: 08$ & $24: 58: 03$ & $24: 58: 58$ & $25: 00: 53$ & $25: 01: 55$ & 25:02:55 & $25: 49: 50$ & $25: 51: 15$ & $25: 52: 10$ & $25: 54: 14$ & $25: 56: 09$ & $25: 57: 04$ \\
\hline & Departure & $24: 56: 18$ & $24: 58: 13$ & $24: 59: 08$ & $25: 01: 10$ & & $25: 03: 35$ & $25: 50: 30$ & $25: 51: 25$ & $25: 52: 29$ & $25: 54: 24$ & $25: 56: 18$ & $25: 57: 14$ \\
\hline \multirow{2}{*}{$\mathrm{N} 12$} & Arrival & $25: 11: 25$ & $25: 13: 20$ & $25: 14: 15$ & $25: 16: 10$ & $25: 17: 05$ & $25: 18: 00$ & $23: 43: 34$ & $23: 44: 44$ & $23: 46: 39$ & $23: 47: 34$ & $23: 49: 28$ & $23: 50: 25$ \\
\hline & Departure & $25: 11: 35$ & $25: 13: 30$ & $25: 14: 24$ & $25: 16: 19$ & $25: 17: 15$ & $25: 18: 09$ & $23: 43: 59$ & $23: 44: 54$ & $23: 46: 49$ & $23: 47: 44$ & $23: 49: 39$ & $23: 50: 35$ \\
\hline \multirow{2}{*}{$\mathrm{NI3}$} & Arrival & $25: 27: 27$ & $25: 29: 22$ & $25: 30: 17$ & $25: 32: 12$ & 25:33:07 & $25: 34: 02$ & $23: 51: 30$ & $23: 52: 25$ & $23: 53: 19$ & $23: 55: 15$ & $23: 57: 10$ & 23:58:05 \\
\hline & Departure & $25: 27: 36$ & $25: 29: 31$ & $25: 30: 27$ & $25: 32: 22$ & $25: 33: 17$ & $25: 34: 12$ & $23: 51: 40$ & $23: 52: 35$ & $23: 53: 29$ & $23: 55: 25$ & $23: 57: 19$ & $23: 58: 15$ \\
\hline \multirow{2}{*}{$\mathrm{N} \mid 4$} & Arrival & $25: 47: 45$ & $25: 48: 45$ & $25: 50: 45$ & $25: 51: 45$ & $25: 53: 45$ & $25: 54: 44$ & $23: 58: 45$ & $23: 59: 45$ & $24: 01: 45$ & $24: 02: 45$ & $24: 04: 45$ & $24: 05: 45$ \\
\hline & Departure & $25: 48: 00$ & $25: 49: 00$ & $25: 51: 00$ & $25: 52: 00$ & $25: 54: 00$ & $25: 55: 00$ & 23:59:00 & $24: 00: 00$ & $24: 02: 00$ & $24: 03: 00$ & $24: 05: 00$ & $24: 06: 00$ \\
\hline
\end{tabular}

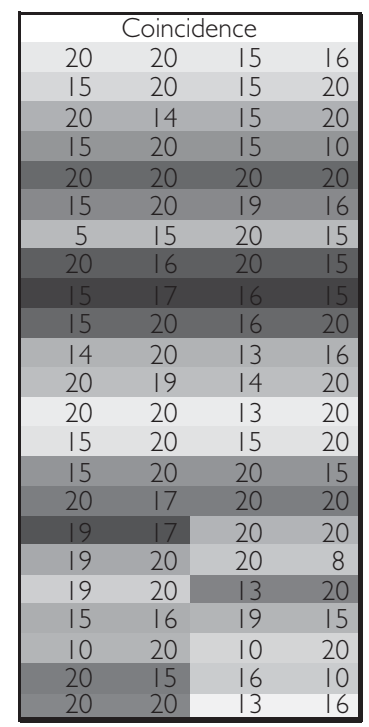

me represents each coincidence (some colours are repeated, so the first time they occur represent the overlapping time of the first time they appear in the previous table).

In the following table, the time differences of initial and final timetables are presented. The intensity of the colour is related with the overlapping time. The main schedule changes are in the middle of the table and need to be anticipated several stations in advance.
The cumulative distribution function of the overlapping time for the second case is depicted in Figure 2. The high frequency of the maximum value (20 seconds) means that there is room to increase this limit (established by the current processes) and therefore to increment the total coincidence time. Many overlapping times correspond to intervals greater than 10 seconds.

\section{Conclusions}


Table 2

Time differences between timetables (optimal timetable calculated optimizing only departure times)

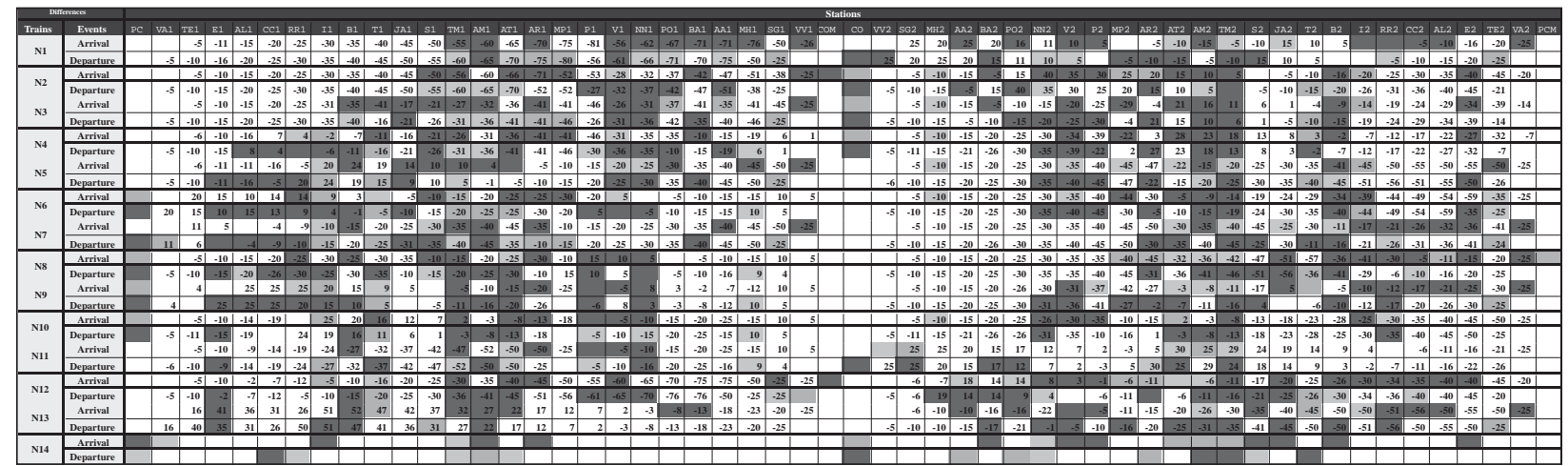

Table 3

Time differences between timetables (optimal timetable calculated optimizing arrival and departure times)

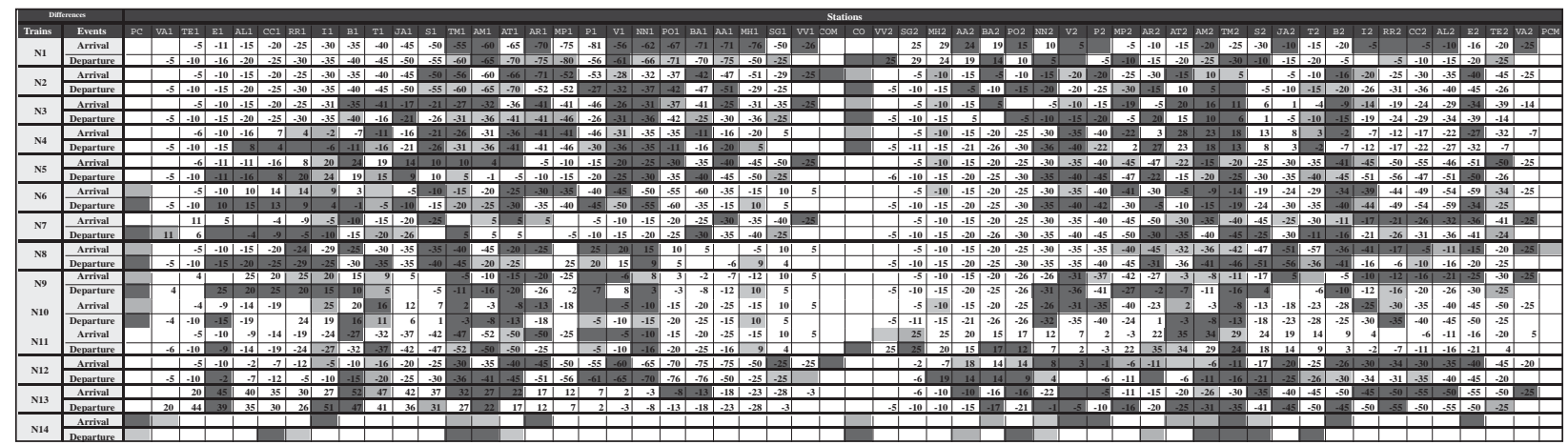

The model presented in this paper is a decision support tool that can be used for maximizing the overlapping time between the slow-down and speed-up processes of underground trains in order to achieve energy savings. This problem has been formulated as a MIP optimization problem with a combinatorial nature and very difficult to solve. However, quasioptimal solutions can be obtained in a reasonable amount of time and show the dramatic potential savings achievable.

Figure 2

Cumulative distribution function of overlapping time

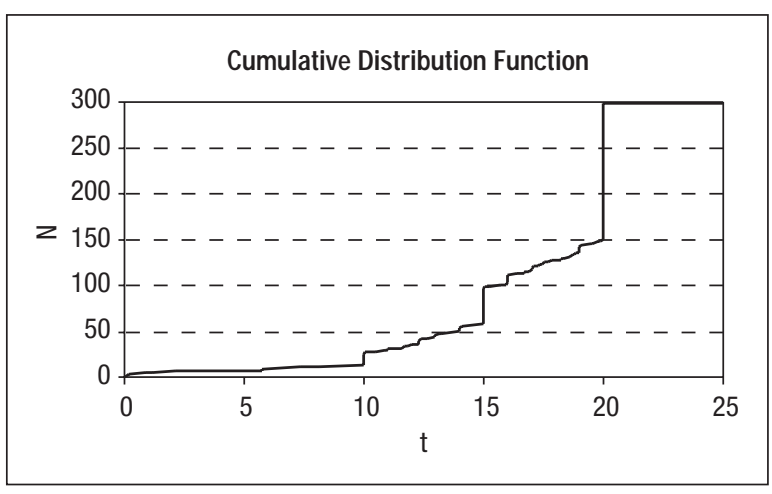

As observed in the case study most of the overlapping time is achieved without modifying the current advertised timetable and, therefore, with no public knowledge.

This model can be easily extended to consider several underground lines supplied by some coincident electrical substations or more trains in the same line (night and early bird trains, for example).

With this formulation it can be possible to count overlaps among multiple trains (more than two). Multiple overlaps have been manually accounted for and represent a $0.5 \%$ of the total overlapping time estimated by the model for this case study, mainly due to the scarcity of the night trains. However, a future extension of the model has to include this possibility.

\section{Acknowledgements}

The authors of the paper acknowledge the collaboration of Metro de Madrid in providing data and following the model development. 


\section{References}

ADINOLFI, A.; LAMEDICA, R.; MODESTO, C.; PRUDENZI, A., and VIMERCATI, S. (1998). Experimental assessment of energy saving due to trains regenerative braking in an electrified subway line. IEEE Transactions on Power Delivery, Volume I3, Issue 4, Oct. 1998 Page(s): I 536- I 542.

BROOKE, A.; KENDRICK, D.; MEERAUS, A., and RAMAN, R. (2005). GAMS A Users Guide. GAMS Development Corporation (www.gams.com)

BUSSIECK, M.R.; WINTER, T., and ZIMMERMANN U.T. (1997). Discrete optimization in public rail transport. Mathematical Programming, 79(3), (I997), 4I5-444.

CAPRARA, A.; FISCHETTI, M.; GUIDA, P.L.; MONACl, M.; SACCO, G., and TOTH, P. (200I). Solution of real-world train timetabling problems Proceedings of the 34th Annual Hawaii International Conference on System Sciences 200I.

CAPRARA, A.; FISCHETTI, M., and TOTH, P. (2002) Modeling and solving the train timetabling problem. Operations Research Sept.-Oct. 2002, vol. 50, no. 5, pp. 85 I-6.
ILOG (http://www.log.com/products/cplex/)

GODWIN, T.; RAM GOPALAN, T.T., and NARENDRAN (2006). Locomotive assignment and freight train scheduling using genetic algorithms. International Transactions in Operational Research 13 (4), 299-332.

NIELSEN M. N.; HOVE, B., and CLAUSEN J. (2006). Constructing periodic timetables using MIP - a case study from DSB S-train. International Journal of Operational Research Volume I, Number 3 / 2006 Pages: 213-227.

RODRIGUEZ, J. (2007). A constraint programming model for real-time train scheduling at junctions. Transportation Research, Part B (Methodological) Feb. 2007, vol. 4I, no. 2, pp. 23।-45.

SEMET,Y., and SCHOENAUER (2005). An efficient memetic, permutation-based evolutionary algorithm for real-world train timetabling. The 2005 IEEE Congress on Evolutionary Computation, Volume 3, 2-5 Sept. 2005 Page(s): 27522759. 